\title{
Comunicación

\section{El perfil comunicativo de los huicholes que viven en la ciudad}

MAGDA JURÁNKOVÁ*

En este artículo se analiza el perfil comunicativo de los huicholes que viven en la ciudad, poniendo énfasis en el uso que le dan a los celulares. La manera en que usan los celulares está moderada por razones económicas y culturales. Les sirve para ser ubicables, para poder comunicarse con sus familiares en la sierra y, a su vez, porque el mundo occidental en el que se mueven (estudios, trabajo), lo exige. Los huicholes se sienten satisfechos con las funciones básicas que tienen sus celulares. No investigan todas las posibilidades de este medio, ni se interesan por las innovaciones. No están dispuestos a comunicar a cada paso, tienen otras preferencias. Les gusta la convergencia de las tecnologías en el celular, pero ellos mismos dicen que no hay que exagerar.

PALABRAS CLAVE: huicholes, medios, celulares, gratificación, uso moderado.
I present the communication profile of the huichols who live in the city. I concentrate in the use of the mobile phones. The use of mobile phones is moderate because of the economic and cultural reasons. The mobile phones serve them for being located, for the communication with its families who live in the communities in the mountains, at the same time, the occidental culture own of the life in the city, it demands. The huichols are gratified by the basic functions of its mobile phones. They don't investigate the possibilities of this media, they aren't interested in the technological innovations. They aren't ready to communicate constantly, they have other preferences. They themselves say that don't want exaggerate the use of this media.

KEY WORDS: huichols, mass media, mobile phones, gratification, use moderate.

* Universidad de Carlos en Praga.

Correo electrónico: magda.agata@email.cz 
En primer lugar, en este artículo, presento algunos rasgos de la cultura huichola, importantes para comprender su apropiación de los medios de comunicación. En segundo lugar, me centro en su perfil comunicativo y apropiación de los medios, con el acento en el uso de los celulares y las nuevas tecnologías en general. En el caso de los huicholes que viven en la ciudad intervienen dos aspectos: los usos que hacen de los medios de comunicación en la ciudad y en la sierra.

El perfil que presento está hecho con base en la observación ${ }^{1}$ y en entrevistas semiestructuradas2 (Taylor y Bogdan, 1998; Baz, 1999, Geertz 1988).

Por ciertos problemas que tuve en mi investigación me di cuenta de algunos rasgos culturales de la sociedad huichola. Un primer problema

1 Los observé en tres ámbitos, pero cada uno con diferentes significado y utilidad. En primer lugar utilicé la observación participante, en el de encuentro de los huicholes en Zapopán. Ahí pude entrar a la comunidad de los huicholes que viven en Guadalajara, donde los informantes me presentaron a otros huicholes en sus encuentros domingueros, y así sucesivamenye (técnica de bola de nieve). En este sitio realicé algunas entrevistas y concerté otras. Socialmente, mi papel de "participante como observador" era reconocido. De la misma manera actué en la comunidad de San Andrés, en la sierra, a donde fui durante tres días con mi profesora Sarah Corona Berkin para aplicar la evaluación externa del bachillerato intercultural. Todos sabían que era una estudiante que aplicaba una evaluación e investigaba su perfil comunicativo. Puede observar el uso de los medios en general, y también entrevistar a los niños que veían caricaturas en la televisión, su sala de computación, biblioteca, uso de teléfono, tanto público como en tiendas. En tercer lugar, observamos si durante las clases, en la preparatoria en Estipac donde estaba aplicando la evaluación externa, utilizaban los celulares, que es cuando se nota el enganche con la tecnología celular y la necesidad de relación constante e ininterrumpida con los otros.

2 En la ciudad, logré entrevistar a cuatro hombres entre 20 y 35 años que estaban estudiando una carrera universitaria, trabajaban y tenían celular; un hombre de esa misma edad, que estudiaba, trabajaba y no tenía el celular, y un hombre de ese mismo rango que trabajaba (no tenía estudios) y tenía celular. Entrevisté tambien a una mujer de 25 años que trabajaba en la ciudad, no tenía estudios, pero tenía celular. 
consistió en conseguir citas con mujeres 3 ; otro fue conseguirlas con huicholes de edad 4 .

Mi conclusión es que en la cultura huichola las mujeres no tienen la costumbre de hablar en el espacio público mestizo, y con los mestizos, si no es necesario. Otra conclusión hipotética es que las huicholas, para representar la comunidad huichola ante los mestizos, dejan ese papel al hombre.

\section{LA LENGUA, EL TIPO DE LECTURA Y LA CULTURA}

Según Sarah Corona Berkin, los huicholes son uno de los 54 grupos indígenas de México con mayor porcentaje de monolingüismo, es decir, que únicamente hablan su lengua. (Corona, 2002a: 73) ${ }^{5}$ Su lenguaje 6 tiene dos

3 Mis informantes me presentaban más a hombres que a mujeres, a las que era díficil localizar. Sí, las encontraba en Zapopan (encuentro dominguero), pero no logré entrevistarlas en ese sitio, porque no estaban solas, sino en el entorno de sus amigas. No hablaban conmigo, yo tenía que empezar y continuar la charla con todas. Los hombres, al contrario, hablaban conmigo, se acercaban preguntándome por mi investigación, por mi estancia en México.

4 Con los huicholes de edad tenía otro problema, pues siguen viviendo en la sierra; solamente tuve una oportunidad de hablar con una pareja de edad en la ciudad. En la sierra no tenía la oportunidad de hablar con ellos, porque además de la diferencia de lenguas, no eran muy comunicativos.

5 Hay muchas diferencias en los datos sobre los pueblos y lenguas indígenas. El problema está en que hay un desconocimiento sobre la cantidad de indígenas que hay en el país, por la invisibilidad y negación con que se les trata.

6 El huichol está emparentado con el náhuatl, así como con el pima, el yaqui, el pueblo, el cora y el tepehuano, que forman parte de la familia yuto-azteca. Tanto el cora como el huichol forman un subgrupo dentro del grupo sonorense de la rama meridional. Los huicholes utilizan la expresión tewi niukiyari, que significa "palabras de la gente", para designar a su propia lengua. El huichol contiene préstamos importantes del náhuatl y del español. (http://cdi.gob.mx/ini/monografias/huicholes.html 22.8.2005)

Durante sus viajes sagrados a Wirikuta, los peregrinos cambian sus nombres y el lenguaje se trastoca; los dobles sentidos y los acertijos se vuelven 
formas de empleo: el cotidiano y el religioso, y apenas en 1985 se inició la forma actual de escribir su lengua 7 . Existen unos cuantos textos impresos en huichol, y pocos son los que saben leer y escribir la lengua. No obstante, su escritura se enseña en las escuelas interculturales en la sierra (la primaria, la secundaria y el bachillerato), y en el Departamento de Estudios de Lenguas Indígenas (DELI) de la Universidad de Guadalajara, pero son escasos los libros en huichol y los escritores huicholes. Las actas de las asambleas indígenas, así como las cartas personales y de amor se escriben en español. (Corona, 2002b: 23)

Según José Luiz Iturrioz Leza, para los huicholes la naturaleza es un libro en que sus antepasados han escrito su memoria y su saber. Y hacerse sabio consiste en saber leer esa escritura. La cultura huichola se convierte en un código para descifrar la escritura sagrada de la naturaleza. La que no se podría entender sin el conocimiento transmitido por los antepasados, pero el conocimiento de estos se lee en el libro de la naturaleza. (Iturrioz, 1995: 85-86)

Se nota la importancia existencial de la interpretación y diferente tipo de lectura en el mundo huichol, a pesar de que la relación entre la historia (conocimiento de ser huichol) y la naturaleza tiene la definición en el círculo.

Iturrioz dice que los hombres ${ }^{8}$ deben aprender a leer e interpretar (descubrir el sentido) las huellas de antepasados dejadas en su peregrinaciones por los territorios sagrados. Los huicholes tienen una noción tan desarrollada de escritura, manifiesta en el hecho de que tienen varias palabras $^{9}$ para los conceptos de lectura y escritura, así como para expre-

comprensibles para los iniciados, y así la habilidad traductora es condición de sobreviviencia y de crecimiento espiritual.

7 El acceso de los huicholes a la TV fue un verdadero "boom" en la sierra. Ya los niños huicholes pasan, como cualquier otro niño, su primera socialización en el entorno de la televisión y se apropian de la cultura audiovisual.

8 La separación de las tareas y trabajos por género es uno de los rasgos importantes de la sociedad huichola.

9 'uxatsiya: pintar figuras con significado; 'triya: retratar, copiar, grabar, imitar; 'utiarika: pintar, dibujar, escribir; teriwariya: leer; teriwarika: llamar, nombrar. 
sar la relación entre significados y significantes, que no han necesitado importar ni inventar nuevos términos para entederla. (ibid.: 86)

La actividad de leer, a pesar de que no tenían la escritura ni la sabían, no era desconocida para los huicholes, solamente el significado de leer ha sido diferente.

La espiritualidad y la religiosodad influye en el modo de ser de los huicholes, en el modo de ver el mundo, en su punto de vista.

El huichol siembra, caza y participa en las mismas ceremonias que sus antepasados. Para él, el mundo tiene una dimensión sagrada que es considerada de gran poder y cuya manipulación está a cargo de especialistas como los mara'akame, quienes por medio del sueño penetran en el mundo de los dioses estableciendo un nexo entre lo sagrado y lo profano.

Según Ari Rajsbaum Gorodezki, los huicholes tienen su propia concepción sobre su origen e historia, en donde la memoria colectiva se refiere a aquellos hechos que tienen una significación cósmica. Para ellos, la historia "cósmica o verdadera" se encuentra plasmada en los mitos, en el arte y en todas las manifestaciones simbólicas del pueblo.

Los mitos son el modelo de todas las acciones que tienen sentido en la sociedad. Su mitología, en general, hace referencia al maíz, al venado y al peyote, por lo que los rituales, las fiestas, la organización material y temporal de la vida gira muchas veces alrededor de ellos ${ }^{10}$, y donde sus formas de expresión artística reflejan sus sentimientos religiosos.

Para los huicholes, la palabra es muy poderosa, pero la pronunciada, ante todo, por el mara'akame.

Según Corona, su cultura se aprende viendo, oyendo, sintiendo, memorizando (no por los libros, ni la escritura). La ceremonia religiosa de

Los nombres de medios técnicos son tomados del español (grabadora, cámara). (ibid.: 86)

10 El maíz y el venado representan el sustento vital, en tanto que el peyote es el medio más importante para trascender el mundo profano y la manifestación material más obvia de lo sagrado. Los dioses son considerados como antepasados, en tanto que los parientes muertos pueden llegar a ser semidivinizados. De esta manera, la muerte establece un lazo más con lo sagrado. (http://cdi.gob.mx/ini/monografias/huicholes.html 22.8.2005) 
Yuimakwaxa, dedicada a los niños, les enseña a confiar en sus sentidos: el oído y la narración son sus brújulas. (Corona, 2002b: 25) La importancia de la narración tiene la base en su religiosidad y espiritualidad; a partir de ahí se desarrolla su vida social.

Según Corona, dado que, entre otros, la escritura de los huicholes tiene apenas 20 años de existencia, y que las escuelas donde se enseña la lectoescritura en español no ha alcanzado a toda la población, la forma escrita de comunicación no es una práctica muy común, aunque es altamente valorada. El orden lineal, el punto fijo, la toma de distancia, la separación entre el productor y el texto, y el texto y el lector, propios de la forma escrita, son más o menos ajenos al mundo huichol. La oralidad, que ha caracterizado a la comunidad por varios siglos, propone otras formas de registro, relación y disciplina corporal.

Frente al registro escrito, que organiza los contenidos por temas y los elabora con un mínimo de repetición, se encuentra la memoria como lugar de registro de la oralidad, junto con otras estrategias: la repetición, la narrativa, la sintaxis rítmica, el canto y el didactismo. Estas características conforman un texto oral ${ }^{11}$, que para perdurar en la memoria recurre a la repetición de ideas, frases, estrofas, ritmo y música que involucran el cuerpo completo, se sistematizan las ideas en torno a narraciones de sucesos y acciones de personajes que, finalmente, aportan didácticamente, reglas para vivir.

El registro del recuerdo oral es la forma más elaborada de pensamiento de una comunidad oral; la memoria y la transmisión oral de la cultura huichola nos ilustran. Los mara'akate, en un entrenamiento en

11 Iritemai Pacheco Salvador describe los géneros de la tradición oral huichola desde los géneros con carácter educativo ('Ixatsika), las canciones o textos compuestos para ser cantados (Kwikari), las composiciones destinadas a ser cantadas, donde se incluyen las canciones y composiciones narrativas (Niawari), los cuentos humorísticos, anécdotas (Niuki/ Yatsika Munanaiyikire), el género de los rezos (Nenewierika), el canto de mara'a kame (Tunuiyari(ka) o Tunuari $(k a)$ ), hasta Xiawaurika, discurso de los padres del pretendiente para pedir la mano de la novia. El discurso de pedir la mano empieza por narrar el comienzo del mundo y la mitología. (Pacheco, 1995: 186-190) 
este oficio, transmiten en sus cantos -de contenidos religiosos, éticos, políticos, de justicia, históricos, pertenecientes a su cultura- no sólo la singularidad de su persona y su capacidad nemotécnica y largo entrenamiento, sino también la forma de pensamiento y comunicación que caracteriza a la comunidad. (ibid.: 28-30)

La cultura huichola tiene un origen oral, configurada para el recuerdo oral -para ser narrada-; su transcripción a la escritura ya no es un rasgo propio de ella.

Según la investigación que hizo Corona (idem), con fotos y personajes huicholes, les gustan las cosas contextualizadas, tienen la necesidad de ver y conocer el contexto para comprender la totalidad.

\section{COMUNICACIÓN, CULTURA AUDIOVISUAL}

\section{Y MEDIOS DE COMUNICACIÓN}

Los huicholes no viven en el mundo donde las imágenes y los videoclips (cultura audiovisual) son algo cotidiano, como en la cultura Occidental, donde son tan habituales que ya ni le prestamos atención 12 .

El acceso a los medios (lo audiovisual en general) está limitado por la escasez de recursos económicos ${ }^{13}$ y energéticos.

12 Según Corona, las imágenes occidentales que los huicholes reciben, son las imágenes de los libros de texto, las pocas fotografías que los visitantes hacen llegar a la comunidad, las fotografías para documentos oficiales y las etiquetas de los escasos productos que venden en las tiendas. En San Miguel no hay publicidad, carteles, periódico, ni espejos que permitan ver el cuerpo completo. Los muros de casas, ni por dentro ni por fuera, se decoran habitualmente, ni son comunes los calendarios con fotografías. En las escuelas no hay carteles ni decoraciones con imágenes o fotografías en aulas. (Corona, 2002b: 26-27)

13 Según Biglow, la gente con su ingreso regular adquiere las televisiones y videos por crédito de dos o tres años. Son las cosas que muestran el estatus de la persona. Para crear la electricidad necesaria para ver la televisión o el video, en el caso de San Miguel, usan el generador de gas de la clínica. (Biglow, 2001: 47) 
En la sierra no hay libros en las casas, no hay acceso diario a los periódicos. Estos están solamente en las escuelas, si no olvidan pedirlos ${ }^{14}$.

Tampoco editan su revista por la escasez del dinero. Los huicholes que viven en la ciudad monitorean los periódicos, y cuando hay alguna noticia sobre ellos, lo guardan, y cada tres meses completan algo como una revista/periódico de estos anuncios, los llevan a las asambleas y a la sierra.

Los huicholes no están presentes en la televisión, ningún conductor es indígena, no hay programas en lenguas indígenas ${ }^{15}$, no hay actores indígenas. Los huicholes tienen el mismo destino que todos los grupos marginados, atraen la atención de los medios de comunicación cuando garantizan que el asunto es tan atractivo o tiene la potencia de la sensación que atrae al gran público. Sin embargo, están realmente encantados con los programas donde no pueden reconocerse, por ejemplo: las telenovelas.

El único medio de comunicación donde su lengua está presente es la radio: la estación del Instituto Nacional Indigenista (INI) en Jesús María, "La voz de los cuatro pueblos", (Corona 2002b: 22), donde se transmiten los programas en cuatro lenguas indígenas, incluido el huichol.

Esta estación se encarga de dos cosas: emitir los programas en huichol y mandar los recados. La radio es el único medio masivo de comuni-

14 En la intercultural (Tatu'utsi Maxakwaxi) en San Miguel, Corona Berkin inició el proyecto de la integración del periódico en la materia de español, con el objeto de aprender y ejercitar la lectura y la escritura, desarrollar sus competencias para examinar críticamente todos los tipos de informaciones presentados en el periódico (gráficas, fotografías, palabras) y reflexionar sobre diferentes temas, incluso temas políticos. Después de utilizar el periódico en la clase, el alumno lo lleva a su casa, así la prensa entra en los hogares. El periódico Público dona los ejemplares que se entregan en Ixtlán del Río, Nayarit, de donde son enviados en avioneta a la sierra una vez por la semana. (Corona, 2004: 170, 189)

15 Según Martín-Barbero hay millones de hombres y mujeres que deben renunciar a su lengua materna para acceder a los medios de comunicación. (Martín - Barbero 2002: 29) 
cación al que tienen acceso diariamente 16 a través de aparatos de pilas. Algunos jóvenes huicholes tienen walkmans que les permiten además oír casettes de música grabada, ya sea de grupos de banda norteños comprados en la ciudad, o de grupos huicholes grabados por pequeñas compañías de grabación o casettes grabados por ellos de la radio y durante eventos en su comunidad. (Corona, 2002a: 73)

Los huicholes tienen el hábito de escuchar la radio y tienen acceso relativo (por la venta) a la televisión y al video (no pueden escoger el programa, este se ve colectivamente), e igualmente al celular17.

La comunicación electrónica (por internet o celular) no es ajena al mundo huichol; este idioma lo aprenden por sí mismos; como todos, son autodidactas. Los estudiantes tienen acceso a internet en las escuelas $^{18}$, pero no saben manejarlo rutinariamente. Lo utilizan, pero no tienen el "capital informático" para comprender las posibilidades de él y manejarlo bien.

Sin embargo, a pesar de que para acceder a los medios de comunicación los huicholes deben renunciar a su lengua materna, y a pesar del acceso limitado a esos medios en la sierra, los huicholes interactúan con los medios pero les hace falta formar el capital informático para saber manejarlos. Pero, ¿cómo se comunican entre sí en la ciudad?, ¿cómo se apropian de los medios?

\section{ENCUENTRO DOMINGUERO}

La cultura de los huicholes está basada en la comunidad, lo comunitario. Quienes salen a la ciudad para trabajar y/o estudiar, se trasladan

16 Según Corona, los jóvenes en San Miguel Huaixtita escuchan dos o tres horas diarias de radio y hasta nueve los fines de semana: $80 \%$ escucha noticias, $58 \%$ de las mujeres escucha radionovelas y $42 \%$ de los hombres también. (Corona, 2002b: 35)

17 Según Biglow, en la primavera de 2000 fue construida una torre para obtener señal, en estos aparatos y por eso llega a los sitios más altos de la sierra. (2001: 14)

18 No obstante, hay pocas computadoras para tantos estudiantes, pocas clases de computación. 
físicamente de su comunidad pero siguen actuando como miembros de ella, lo social y lo comunitario es mucho más importante que lo individual, se comportan como los miembros de su comunidad, no como individuos; su socialización en la comunidad es muy marcada.

La segunda socialización en la ciudad no cuestiona su sentido de miembros de la comunidad huichola, mejor dicho, no corren el riesgo de debilitar el sentido comunitario de ser huichol. Cuando les pregunté a los huicholes qué querían hacer después de acabar su carrera en la ciudad, me respondieron que volver a la sierra y ayudar a su comunidad 19 .

Les parece raro cuando algún huichol quiere quedarse en la ciudad para toda su vida (a pesar de esto, muchos huicholes lo hacen por causa del trabajo), lo que significa alejarse del mundo huichol y, en el caso extremo, dejar de ser huichol. Para enfrentarse al mundo occidental, que tiene un estilo de vida totalmente diferente (que no comparte su religión, que tiene otras pautas de comportamiento, que es más individualista que comunitario), buscan y necesitan el apoyo de los otros huicholes, porque no están acostumbrados a actuar en el espacio público como individuos.

Para compartir el tiempo con su "gente", los huicholes se encuentran cada domingo por la tarde en Zapopan, jugar baloncesto o futbol. Fui siete veces a dicho lugar, dos veces en compañía de los huicholes y otras veces sola, esperando encontrar a unos amigos. Ví los partidos de baloncesto, pero no los de futbol, que juegan en equipos mixtos y separados según $\operatorname{sexo}^{20}$.

Esos partidos son un poco como un ágora griega, como el sitio de encuentro. Todos los huicholes que están viviendo en la ciudad saben que el domingo por la tarde pueden encontrar a otros huicholes en Zapopan, y que allí pueden hablar entre sí y salir a pasear por la plaza

19 Realmente solo conozco a un huichol que no actúa como miembro de la comunidad huichola sino como individuo; me respondió que después de acabar la carrera querría viajar.

20 Muchas chicas juegan con zapatos de tacones porque vinieron sin intención de jugar; otras en su vestimenta tradicional o con la cotidiana. Los hombres no juegan con su vestimenta tradicional, sino con su vestimenta cotidiana o de deporte. 
donde se presenta la posibilidad de hablar con la persona que les gusta mientras dan vueltas.

Estos juegos ocupan un sitio muy importante, en mi opinión el más importante en la comunicación de los huicholes en la ciudad ${ }^{21}$. Los huicholes no se comunican mucho entre sí por internet, que es la forma más barata de comunicación; solamente los estudiantes que tienen este acceso en la escuela. A los cibercafés van muy poco. Muchos huicholes no tienen teléfono fijo en casa; los celulares los utilizan según el estado de su saldo, por eso la forma más sencilla de encontrarse es durante los partidos. Además se habla sobre la situación en las comunidades y sobre los eventos que se van a hacer.

La importancia del encuentro y de la forma de comunicarse entre los huicholes es evidente en el siguiente ejemplo: no pude encontrar (durante cuatro meses) a una chica porque cambió su número de celular; su primo no tenía el número nuevo de ella, me dio el fijo de casa de su hermano (al que tardé en encontrar en casa), pero este tampoco tenía tal número. Fui a Zapopan, encontré a otro primo de ella, me dijo que no la había visto desde hacía un mes y que tampoco tenía su número nuevo; una amiga de ella me respondió lo mismo y que no se había acordado de pedirle su número nuevo en el último encuentro porque siempre era aquella chica quien la llamaba y no viceversa, además la amiga suponía que aparecería cualquier domingo; si no venía, era porque tenía mucho trabajo.

Por este ejemplo queda claro que los huicholes no están enganchados con sus celulares; los utilizan para comunicarse con sus compañeros de clase que no son huicholes o con su familia en la sierra; como medio de comunicación con los otros huicholes en caso de emergencia, cuando no pueden esperar hasta el domingo para encontrarlos. En este ejemplo se nota la importancia de los encuentros, de un espacio y tiem-

21 Mis informantes mencionaron en las entrevistas la importancia de los encuentros domingueros como la única posibilidad de encontrar a otros huicholes, sin tener celular; también contaron cómo les había servido este encuentro como guía, pues durante las entrevistas los orienté cuando recién habían llegado a la ciudad. 
po fijo22 para hablar con seguridad a amigos huicholes o a los amigos de amigos huicholes, dejar recados, compartir todo con "su gente" y ver a la persona que a uno le gusta.

Sin embargo, no se ven las parejas hablando solas, el sitio de encuentro es público y no da la posibilidad del íntimo encuentro. Para este sirve la plaza de Zapopan, adonde se va después de los partidos; aquí, ya en la compañía de sus amigas, y sin la presencia de los otros huicholes, la chica puede encontrar al chico que le gusta y viceversa ${ }^{23}$.

La importancia de los encuentros se nota en otro caso que me tocó observar. Un domingo asistió al encuentro una pareja de edad en su vestuario tradicional; me sorprendió porque nunca en el encuentro dominguero había visto una pareja de mayores. Empecé a hablar con ellos, el hombre me dijo que habían venido a consultar a un médico. Ya llevaban una semana en la ciudad y no les gustaba, pero sabían sobre el encuentro dominguero, adonde acudieron para encontrar a los otros huicholes, para informarse, pedir ayuda y compartir la tarde. Menciono este ejemplo por dos razones: la primera razón es que ilustra la importancia del encuentro dominguero para orientar a los huicholes en la ciudad; otra razón es que ilustra el comportamiento de las mujeres huicholas. A pesar de que dirigí mis preguntas a ambos, solamente el hombre me respondió, la mujer se quedó callada, no me dijo ni una palabra ni hablaron entre sí durante mi entrevista con ellos, mejor dicho, con su esposo. Pudo ser que la mujer no supiera español o pensara que sería más conveniente que el hombre hablara, como su representante en el espacio público.

22 Para encontrarse en la ciudad, los huicholes llevan reloj, pero no son puntuales. Mis informantes me dijeron que en la sierra no hacía falta llevarlo cuando uno trabajaba en lo suyo.

23 La importancia del encuentro en el partido y siguiente encuentro en la plaza, para los jóvenes huicholes, se nota en otro caso. Una vez, un domingo por la tarde, salimos a jugar billar al centro de la ciudad. A pesar de que estábamos jugando en el centro, fuimos luego a Zapopan para que las chicas vieran y encontraran a sus amigos huicholes, porque de lo contrario perderían la posibilidad de verse, lo que será hasta el siguiente domingo (día en que descansan). 
A los partidos del domingo van todas las familias, los niños juegan con los otros niños y los padres juegan baloncesto; los niños hablan mucho en español porque ya viven desde pequeños en la ciudad y estudian con los mestizos; los padres y otros huicholes hablan entre sí en la mayoría de los casos en huichol, y conmigo en español para que entendiera, pero los asuntos de la comunidad -el anuncio sobre el torneo, la petición de ayuda a una comunidad, los problemas con los papeles- fueron presentados en español.

El encuentro dominguero sirve para jugar baloncesto o futbol, para informar sobre los asuntos en las comunidades, para hablar con los otros huicholes, para compartir la tarde con "su gente", para pasar los recados, para orientarse en la ciudad, para encontrar a sus amigos y también para ver a sus "futuras novias".

Los partidos, en sí mismos, no tienen tanta importancia como el acto de encontrarse en el ágora huichola de Zapopan.

\section{PERFIL COMUNICATIVO SEGÚN}

MIS INFORMANTES EN LA CIUDAD

En esta parte presento el perfil comunicativo de mis informantes, ${ }^{24}$ quienes viven en la ciudad, a partir de dos aspectos: el uso y apropiación de los medios de comunicación tanto en la sierra como en la ciudad.

La escritura de la lengua de los huicholes es, en el contexto histórico, un evento realmente nuevo; tiene apenas veinte años, y todavía tres comunidades (San Andrés, Santa Catarina y San Sebastián) no se han puesto de acuerdo sobre algunas palabras a causa de algunos vocablos diferentes. Los huicholes pasan más tiempo con la televisión que con su escritura. Nadie les enseñó la escritura hasta que llegaron los franciscanos. No tenían la necesidad de escribir, porque sus mara'akames contaban de memoria todo sobre orígen, cultura, religión; tampoco tenían la necesidad de dibujarlo, ni necesidad de inventar un calendario.

24 Mis informantes tienen desde veinte hasta treinta y dos años, y tienen siete o hasta diez años que viven en la ciudad. Entrevisté a seis hombres: cinco estudiantes y un huichol sin estudios, y a una mujer sin estudios. 
Ni la mayoría de los mara'akames ni la gente mayor saben escribir (ni en español, ni en huichol) 25 .

En la cultura occidental, con el invento de Gutenberg y luego con los procesos de urbanización, industrialización, democratización, el texto escrito (libro, periódico) se convirtió en el medio de difusión masiva. Por eso, en nuestra cultura el libro y los textos escritos son importantes testigos de la historia y el conocimiento. En el caso de los huicholes no es así, porque para ellos la historia es vivida: vivida en sus fiestas, en sus costumbres comunitarias, conservan lo que les mostraron, enseñaron y dejaron sus antepasados; así en la fiesta actual expresan toda su historia y la cultura dejada por sus antepasados ${ }^{26}$. Por ello no conservan registro escrito de su historia, ni les interesa tenerlo.

En la secundaria Tatuutsí Maxakwaxi, en San Miguel, durante tres años deben escribir un diario. Sin embargo, según mis informantes, la realidad es otra y sólo en el primero lo hacen. Esta es única tarea creativa con la escritura que tienen en la escuela. Lo que los huicholes escriben, son cartas. Estas y los recados eran los únicos medios de comunicación entre los huicholes que radican en la ciudad y sus familias en la sierra, antes de tener celulares y teléfonos fijos en esta.

Mis informantes coincidieron en la compra escasa del periódico y en que por primera vez leyeron el periódico cuando estaban en la ciudad. Solamente un informante vio por primera vez un periódico cuando lo llevaron a su comunidad, porque salía una noticia sobre los huicholes, sobre cómo habían sacado a los "caciques" de sus terrenos, y a mi informante le atraía la foto del paisaje. Otro de mis informantes leyó por primera vez el periódico en la ciudad cuando tenía once años, uno que

25 Apenas hace veinte años que tienen escritura para su lengua; de los pocos libros escritos en huichol (algunos son en ediciones bilingües); no hay periódicos; solamente editan cada tres meses un boletín informativo con las noticias de la prensa que tratan sobre los huicholes o indígenas, en general; no hay revistas ni textos escritos en huichol en internet (lo investigué a través de Google).

26 Así nos explicaron los alumnos la historia y cultura huicholas en la evaluación externa (evaluación a Tatei Yurienaka Iyarieya, Fundación Ford, 2006). 
alguien tiró; le atrajo la foto en la portada (luego robaba el periódico de la casa de su tío, que era maestro).

Los periódicos los compran cuando salen los resultados de los partidos de futbol o las noticias sobre los huicholes. Un informante dijo que agarra el periódico en el tren ligero (dijo que lo agarraba por costumbre). Otro informante lee el periódico de su jefe, los artículos de ciencia. Otro trabaja con el periódico, lee los artículos que le toca leer (como monitoreo de las noticias). Los informantes que trabajan en la ciudad, que no tienen estudios, me dijeron que no leían el periódico.

Lo que del periódico atraía a los huicholes era el material visual (fotos). Los huicholes que trabajan en la ciudad, sin estudiar, no se interesan por el periódico, mientras que los huicholes que a la vez estudian en la ciudad ya se interesan por las noticias que salen sobre sus paisanos o según su afición se interesan, por ejemplo, por el deporte o por la ciencia. Nadie mencionó que leyera la sección social o de cultura, o de economía de algún periódico.

Pregunté a mis informantes sobre su experiencia con los medios de comunicación, ante todo con la prensa, y me dijeron que ocasionalmente los medios se interesaban por ellos, que era una forma de dejarse reconocer como indígenas y a la vez como protección cuando había problemas internos y externos, y que, ocasionalmente, tenían lugar las entrevistas o se hacía una rueda de prensa con ellos.

Vi un reportaje del concierto del grupo "Plástico" que pasó por la televisión local (septiembre 2005), que tenía el objetivo de juntar dinero y ayudar a la comunidad huichola; en el programa apareció uno de mis informantes.

Según las experiencias con la prensa y con los medios en general, mis informantes, que estudian en la ciudad, ya saben que los medios de comunicación pueden ayudarlos para dejarse reconocer, que a través de los medios el gobierno puede darse cuenta de lo que pasa, aunque mencionaban que de vez en cuando los periodistas no comprendían bien el asunto según lo que habían escrito en sus artículos; a la vez saben que sin eventos o asuntos que garanticen un "gran público" -como el evento de Plástico, o como me explicó un informante en el caso de la noticia que había salido sobre él, donde estaba presentado como un delicuente 
bajo el efecto del peyote (salió en los periódicos)-, los medios de comunicación no se interesan por ellos.

De mis informantes, quienes estudian en la ciudad coincidieron en tener ahí una biblioteca pequeña, sobre todo libros relacionados con su carrera, además de manuales. Dependiendo de su personalidad, unos no suelen llevar los libros a la sierra porque se les pueden dañar (los niños los agarran, les atrae la portada del libro), otros los llevan y los leen en sus ranchos (no en sus comunidades) porque allí están solos y se está tranquilo. No tienen libros de literatura mundial, tienen unos libros de cuentos pero no pudieron acordarse de los nombres; uno dijo que le gustó El Príncipe, de Maquiavelo (lo leyó por recomendación de sus maestros), pero es una excepción.

En el contacto con el libro se nota la diferencia en el capital cultural dentro de la sociedad huichola: los familiares de los maestros por primera vez hojearon un libro, antes de que entraran en primaria, en casa de los maestros de la sierra, les atraía la portada; el texto no lo entendían. Los otros informantes, sin ser de las familias de los maestros, por primera vez vieron un libro en la escuela primaria, un manual de español.

Un informante dijo que cuando vio un libro por primera vez, no sabía para que le serviría. Otro informante dijo que cuando por primera vez hojeó un libro en la primaria, no entendía nada de español, que lo que a él le había ayudado a entender habían sido los dibujos. Solamente un informante, cuando contaba su experiencia con los libros, comentó la importancia de lo visual en el proceso de aprendizaje de una lengua extranjera, que para él era el español. Lo mismo le ocurrió con la escritura; copiaba las letras de las cajas de cerveza sin entender, solamente copiaba las letras, mejor dicho, dibujaba las letras en su cuaderno.

A partir de observaciones y entrevistas llegué a una conclusión: que los huicholes prefieren el material visual que el escrito, las fotos al texto, dibujar a escribir.

El libro no conquistó las comunidades huicholas, no hay condiciones para leer, no hay costumbre de leer. En las casas no hay suficiente tranquilidad para leer, ni suficiente espacio privado para leer solo y tampoco suelen tener una biblioteca en casa. A la vez, la lectura del texto escrito no es un rasgo propio de la cultura huichola. 
Sin embargo, a los niños les atraen los libros como un nuevo objeto para jugar e investigar; a pesar de que no entienden, toman el libro para alimentar su curiosidad.

La televisión ha tenido mucho más éxito en las comunidades huicholas. Según mis informantes, en la sierra la tienen solamente los más ricos y la gente con sueldo fijo que trabaja para el Estado. En cada comunidad hay más de diez televisiones. Aunque mis informantes son de diferentes pueblos en la sierra, coincidieron que hacía cinco años que empezó el boom de la televisión en la sierra. Antes estaban en las telesecundarias (a veces ni en la telesecundaria había televisión), pero estas "televisiones" mis informantes no las consideraban como tales porque su uso era y es meramente educativo; la televisión se relaciona con el entretenimiento y hasta con "el vicio". Según uno de mis informantes, la que por primera vez vio en su comunidad, la llevaron los franciscanos para poner películas sobre la vida de Jesucristo y otros temas. Otro informante me dijo que por primera vez vio la televisión en la escuela, que la llevó un maestro. Antes de tener televisión en las comunidades, sus primeros contactos con esta eran en la ciudad.

Los huicholes ven la televisión todas las noches; se juntan en una casa (veinte o treinta personas) para ver las telenovelas ${ }^{27} \mathrm{o}$ los partidos de futbol (unos tienen $S k y$ y cobran diez pesos por ver los programas); los niños ven las películas, les cobran cinco pesos por verlas. Sin la electricidad, la actividad nocturna está restringida, las telenovelas se terminan a las diez y se van a dormir.

27 Realmente están encantados (según mis informantes) con los programas donde no pueden reconocerse, como p.ej. en las telenovelas. Según Martín -Barbero, la telenovela en América Latina se alimenta de la ligazón con la cultura oral, como heredar de ella el predominio del contar, su textura dialógica y carnavalesca, un relato en el que el autor, lector y personajes intercambian constantemente sus posiciones. La "realidad" del relato provoca la confusión entre la narración y experiencia, la experiencia de la vida se incorpora al relato, que narra las peripecias de la telenovela. Es un intertexto que se construye en el cruce de ver la pantalla con el contar lo visto. (Martín-Barbero, 2002: 98, 99) 
¿Por qué a las comunidades, entre la sierra, las conquistó la televisión y no el libro?, por la diferencia entre el carácter de la cultura letrada y la audiovisual, que se acopla mejor con la oralidad de la cultura huichola, lo que Orozco (2001) explica por la existencia de complacencias múltiples entre la oralidad ancestral de las culturas latinoamericanas y la visualidad de la televisión ${ }^{28}$.

Los que no ven la televisión juegan futbol o baloncesto o se sientan para platicar o cantar los cantos que inventan (es una prueba de inteligencia cononcer con qué rapidez se inventan las letras del canto).

Igualmente tienen el video para ver las películas compradas en el pueblo o en el municipio; según mis informantes no graban las películas, sino que las compran en la ciudad y cobran por verlas.

Mis informantes coincidieron en el rechazo de la televisión, al considerarla como un medio malo para los niños, porque estos ya no juegan tanto entre sí, ven la televisión en vez de hacer las tareas. Expresan la postura crítica de Sartori (1998) y de Martín-Barbero (1999), de que no se ve la televisión como un instrumento que se puede aprovechar para cumplir con expectativas educativas, exigiendo la actividad de la familia

28 La diferencia entre la cultura letrada y la audiovisual consiste, según Orozco, en que lo audiovisual se conecta con los sentidos de sus interlocutores (vista y oído) y luego se conecta con la razón (y a veces no), como sucede frecuentemente con las televidencias despreocupadas, fundamentalmente sensoriales y emocionales de las audiencias. Con el texto escrito no pasa lo mismo. Por el grado de abstracción que necesariamente conlleva la palabra, el lenguaje escrito primero pasa por la razón, aunque no sea perceptible, y sólo después llega a los sentidos. Esto, sin embargo, no impide que el texto escrito provoque y evoque emotividad y diversas sensaciones. Según Orozco, existen complacencias múltiples entre la oralidad ancestral de las culturas latinoamericanas y la visualidad de la televisión. El relato audiovisual privilegia lo que se expone, escucha y, ante todo, lo que se ve, percibe y siente. La palabra es el primer sostén del argumento y su paso necesario por la razón hace que su producto natural sea el convencimiento. La imagen es en primer lugar seductora, sus productos inmediatos son la sensación y la emoción. Esto no debe implicar que no se pueda argumentar con imágenes, como tampoco el que no se pueda seducir con palabras. (Orozco, 2001: 65-66, 68-69) 
y de los educadores como los mediadores o comentaristas 29 . No tienen formada una mirada crítica hacia los medios, necesaria para hacer buenas lecturas de los contenidos mediáticos, ante todo, en la situación en la que no tienen acceso a otras fuentes de información. El problema es que usan los medios como meros instrumentos de difusión.

Uno de mis informantes mencionó el problema del mantenimiento de la televisión, porque se descomponían y no había nadie para arreglarlas; en esta situación, piden la ayuda de los mestizos que trabajan en las comunidades.

En la ciudad, los huicholes ven la televisión dependiendo de su tiempo libre; unos diario, y otros solamente de vez en cuando ven las noticias o partidos de futbol o programas que les interesan; un informante mencionó que veía los debates entre los políticos. Cuando salen a su comunidad, a pesar de que hay televisión ahí, no la ven, se dedican a otras cosas.

En la sierra no hay cine, y a pesar de que mis informantes viven en la ciudad, donde tienen la oportunidad de ir al cine y les atraen las películas, no van a él. Unos me dijeron que este les gustaba pero que no iban solos, solamente cuando alguien los llevaba o invitaba; otros simplemente no iban al cine. En el caso de la escasa salida al cine intervienen dos razones, una cultural y otra económica. Los huicholes no tienen tal costumbre, a pesar de que les gustan las películas (de vaqueros, de terror o mencionaban "diferentes", sin especificarlas). Un informante me dijo que cuando había estado en la costa, su padre lo había llevado cada domingo al cine, pero que en Guadalajara no iba porque tenía otras cosas que hacer, no tenía tiempo para ir.

Los huicholes, necesitan el dinero para gastarlo en otras cosas y no en el cine. Los informantes que tenían acceso fácil o gratuito al cine, sí iban. Uno me dijo que había tenido la posibilidad de ir gratuitamente y veía hasta dos funciones al día porque era gratuito, pero que así simplemente, por su decisión, no iba al cine.

29 Los géneros familiares y juvenil-familiares están hechos para que pueda verlos toda la familia, para que puedan estar juntos, compartir, comentarlos $\mathrm{y}$, en este punto, los géneros se pueden aprovechar para presentar, explicar unos valores y comentarlos dentro de la familia. 
En la sierra, los huicholes escuchan la radio diariamente, aunque calculando la duración de las pilas; escuchan la radio mientras están trabajando; escuchan "La voz de los cuatro pueblos" porque ponen los programas en huichol, pasan los recados y pueden grabar lo que les gusta; así escuchaban los partidos de futbol cuando no tenían acceso a la televisión. En la ciudad escuchan las estaciones de Guadalajara, ante todo, las que ponen la música de banda y norteña, o escuchan los CD grabados con esta música.

Solamente los universitarios huicholes tienen el acceso fácil y gratuito a internet en su escuela; navegan y escriben los emails, que representan otro recurso para comunicarse, pero todos mencionaron que escribían emails a sus compañeros de clases o de trabajo, a los maestros o a los huicholes que vivían en otros estados, que lo exigía el mundo occidental en el cual se movían. No suelen salir a menudo a cibercafés, cuando lo hacen gastan menos de cincuenta pesos por mes, y van a estos cuando esperan un email de su escuela o del trabajo. Aprendieron a trabajar con la computadora y el internet en la ciudad. Los huicholes que trabajan en la ciudad, sin estudiar, no utilizan el internet ni para comunicarse.

En ciertas comunidades donde hay escuelas, hay cinco o seis computadoras, pero ya tienen siete u ocho años allí. Solamente pocos niños saben utilizarlas; a pesar de que hay acceso a internet, la mayoría no lo utiliza, solamente los maestros saber usarlo. Según mis informantes, a los mayores no les atraen las computadoras porque están muy ocupados con sus trabajos en la sierra y no les queda tiempo para interesarse por estas tecnologías.

Solamente un informante está interesado en nuevas tecnologías: tiene celular con Bluetooth, en su computadora tiene el messenger para comunicarse con sus amigos en Europa y Japón. Sin embargo, cuando está en la sierra no utiliza internet para comunicarse, se puede decir que allí se desconecta del mundo occidental.

Dos informantes míos me pasaron sus correos electrónicos; uno me pasó dos, pero ninguno funcionó. El otro tardó desde tres hasta ocho días en responderme, si no estaba en la sierra. Cuando estaba en su comunidad no revisaba su correo electrónico, me respondía después de su regreso a la ciudad. 
Los estudiantes que tienen computadora en casa pero sin internet, juegan los juegos de la computadora. No obstante, según lo que dijeron mis informantes, en primer lugar hay tareas y en segundo hay juegos. En su opinión, juegan rara vez.

En todo lo que he expuesto sobre el uso de los medios por los huicholes que viven en la ciudad, se nota una cosa: la falta de entrevistas con los huicholes que solamente trabajan en la ciudad, sin estudiar. Los campos laboral y académico difieren en las exigencias y esto se nota en el uso y la apropiación de los medios.

Los huicholes que solamente trabajan no tienen el acceso tan fácil ni la necesidad de los medios como los estudiantes y, ante todo, no tienen a ningún maestro como guía que les recomiende, explique o forme una postura crítica ante los medios. Los que solamente trabajan en la ciudad no necesitan periódicos, libros, internet o cine para su vida cotidiana, nada les exige usar estos medios, ni les atraen tanto para interesarse por ellos (tienen otras cosas que hacer). Solamente ven la televisión cuando tienen tiempo libre; esto depende del tipo de ocupación a que se dedican en la ciudad. Los domingos, cuando descansan, se distraen con sus amigos huicholes.

Los estudiantes huicholes leen los libros a pesar de que son manuales, leen el periódico, tienen acceso a internet y saben usar por lo menos programas básicos (Word) en la computadora. En la televisión ven las noticias y partidos de futbol, son conscientes de la manera en que les pueden servir los medios, así como los peligros de internet. Ante la televisión todos tienen una postura de rechazo; la perciben como un peligro para los niños si ven películas para adultos, y a la vez como un peligro para su cultura huichola.

Sin embargo, sus usos del libro, internet y de la computadora ${ }^{30}$ son instrumentales, los usan para cumplir con su papel de estudiante/trabajador/huichol. Se sienten a la vez muy responsables con su comunidad y con las obligaciones de un estudiante, y para cumplir con el papel de buen estudiante (tener los conocimientos que pueden enriquecer a su

30 Sobre la percepción de la computadora e internet como el recurso para la movilidad social entre los pobres, que coincide con la percepción de los huicholes, véase Winocur (2004). 
comunidad), se apropian de los medios de la cultura occidental (libro, internet) aunque instrumentalmente.

\section{USO DE LOS CELULARES ENTRE}

\section{LOS HUICHOLES QUE VIVEN EN LA CIUDAD}

He descrito la importancia de los encuentros domingueros para los huicholes ya establecidos o los recién llegados a la ciudad, donde pueden encontrarse sin necesitar ninguna tecnología de comunicación. Esto ya implica cierta diferencia en la apropiación y el uso de los celulares entre los huicholes.

Todos mis informantes ${ }^{31}$ coincidieron en la razón por la que compraron un celular: para poder comunicarse con su familia en la sierra, donde antes del servicio de teléfono público (tiene como un año) ya había celulares. Mis informantes compraron el celular para ser ubicables, para que sus familiares de la sierra pudieran llamarles, ubicarlos en la ciudad. De la sierra les llaman de los celulares de los amigos, familiares o del teléfono público, y viceversa. Así el celular conecta las redes familiares.

Mis informantes coincidieron en usar el celular en los casos de emergencia. Lo usan cuando tienen que arreglar algo urgentemente y no pueden esperar a arreglarlo de otra manera. Esto ilustra un caso que me describió un informante: su hermano vive en la sierra, a menudo viene a la ciudad, pero no lo llama; una vez le llamó; ya tenía tres días en la ciudad, le llamó tres horas antes de volver a la sierra, porque no le quedaba tiempo para comprar un sombrero para su padre, por eso llamó a mi informante para que este lo comprara. Sin embargo, durante su estancia en la ciudad no le llamó.

Uno mencionó que compró el celular para hablar con sus amigos huicholes en la ciudad, para preguntarles dónde estaban y cómo estaban.

31 Entrevisté a cinco hombres (cuatro estudiantes y uno sin estudios) y a una mujer sin estudios, todos con celulares (desde medio año hasta ocho años que tienen celular), y a un huichol estudiante sin celular, para saber cómo se comunican sin este medio. Mis informantes que tienen celular desde hace ocho años, saben que tienen unos de los primeros celulares que salieron, esto les garantizaba cierta exclusividad. 
Dos mencionaron que eran ambas cosas, la necesidad de ser ubicables y las ganas de tener celular (querer tenerlo) como un objeto nuevo, admirable. A la vez mencionaron la importancia del celular para su trabajo, que sus clientes o sus jefes les llamaran.

El celular se ha convertido en el mediador del trabajo. Les llaman de su oficina, les llaman sus clientes, es una oficina en el bolsillo.

Los huicholes tienen los celulares sencillos que cumplen con las expectativas de medio de comunicación, posibilitan lo básico, llamar y enviar mensajes. El uso que hacen del celular es instrumental, se gratifican con las llamadas y mensajes simples.

Todos mis informantes mencionaron la cuestión económica: las llamadas son muy caras, y por eso escriben mensajes a sus compañeros de clase y amigos huicholes. No suelen llamar mucho porque les llaman de sus comunidades y el operador les cobra por recibir la llamada de larga distancia; por eso aunque no llaman y solamente reciben la llamada, pagan. Solamente un informante dijo que tenía el celular para recibir llamadas y mensajes, pero no para enviarlos, porque no comprendía el mecanismo, aunque sabía que le salía más barato.

Por esta cuestión económica prefieren llamar a sus amigos huicholes en la ciudad desde los teléfonos públicos, porque les sale más barato que las llamadas del celular. Si se les acaba el saldo en el celular, compran una tarjeta para llamar desde los teléfonos públicos ${ }^{32}$. Integran ambos tipos de teléfonos.

A la vez, a pesar de tener el celular, no tienen o tienen solamente pocos números de sus amigos huicholes radicados en la ciudad (vi la agenda de un informante mío y la lista de los números no ocupaba ni una hoja).

No están dispuestos a comunicarse a cada momento, mejor dicho, no están dispuestos recibir las llamadas de día y noche. Mis informantes apagan el celular durante la noche para que nadie los moleste. Esto significa que valoran su espacio privado, no están dispuestos a comunicarse continuamente, tienen otra preferencia.

32 Gastan 300, 200, 100 pesos al mes y dijeron que era poco; uno me dijo que tardaba seis meses en comprar tarjeta para celular y que utilizaba el teléfono en la calle, en las tarjetas gastaba hasta 90 pesos al mes. 
Los informantes estudiantes no llevan el celular a sus clases o lo apagan durante sus clases; lo mismo en su trabajo, lo apagan cuando tienen mucho trabajo y necesitan concentrarse. Esto declara un uso moderado del celular y que tienen otras preferencias antes que estar dispuestos a comunicarse a cada momento.

Dan más importancia a otras cosas que a estar dispuestos a comunicarse continuamente, aunque declaran esto como la razón de la compra. En unos casos, por la causa del uso tan escaso del celular, he tenido muchos problemas para ubicarlos.

Solamente un informante me dijo que no apagaba su celular durante la clase porque le ponía el vibrador sin sonido y así reconocía si alguien le llamaba, y que tenía todo el día el celular encendido y que siempre tenía su batería cargada. Sobre no tener celular dijo: "En Guadalajara, ya no, sin celular, no, de repente, todos los números de mis amigos tengo aquí, no los tengo en ninguna otra parte, todos los números, de mis amigos, de mi trabajo, de mis compañeros de escuela, ya no puedo andar sin celular, de repente, quiero hablar a alguien, nada más el celular." Otro informante me describió sus sentimientos cuando se le olvidaba el celular: "Ah, sí, una vez, sabes que, ya, sientes algo como que te hace falta algo, traerlo, se me olvidó, pues mi celular, ya no sabes si le van a hablar o no, pues yo tengo diario, diario comunicación, me hablan diario, pues, de la sierra o de aquí o avisaron la gente o un amigo cómo están y todo, o a veces un cliente también."

En sus casos ya es la costumbre de portar el celular diariamente, ya es parte de su vida cotidiana; entre sus preferencias ya aparece la de estar dispuesto a comunicarse, ser ubicable, que coincide con la razón de comprar un celular.

Otro informante mío tiene la postura contraria, ya no tiene ganas de cargar el celular: "Últimamente, ya me ha pasado el gusto de cargar el celular, ahorita, casi, ya no lo cargo, lo traigo colgado en la casa, porque como que hay mucha gente con los celulares, no me dan ganas, pero a veces sí, hace tiempo que me llaman, mis amigos o mi maestro, entonces a fuerzas tengo que cargarlo, aunque no quiero entonces."

Otra situación que ilustra su uso del celular, es el que le dan cuando están en la sierra. Mis informantes me dijeron que sus celulares los habían comprado, ante todo, para comunicarse con su familia. Esto impli- 
ca que en la sierra, no necesitan el celular porque están con su familia. Unos me dijeron que a pesar de estar haí tenían su celular encendido. Una razón es que su celular presenta uno más en la comunidad, y que los huicholes de la ciudad llaman a este celular para hablar con su familia, para pasarles recados. Un informante lo tienen encendido por el simple hecho de estar dispuesto a comunicar; me dijo que le gente le llamaba y quería que fuera a un lugar y él decía que estaba en la sierra; en este aspecto se acerca al uso del celular en la cultura occidental, en cómo se mueve en la ciudad. A pesar de esto, todavía guarda su espacio privado: apaga el celular durante la noche.

En la sierra cargan los celulares en los motores de sus camionetas o cuando están viendo la televisión, aveces pagan por cargarlo.

Esto ilustra la utilidad de los celulares en la comunicación entre los huicholes y su uso moderado. Sin embargo, cada huichol se apropia del celular según su personalidad; por eso existen excepciones que cumplen con el fin del celular, estar dispuesto a comunicarse (tener el celular encendido), aunque solamente durante el día.

La comunicación por los celulares es inmediata, los usuarios están acostumbrados a respuestas inmediatas. Cuando no obtienen la respuesta inmediata, las emociones (enojo, coraje, desesperación) se filtran a través de este medio de comunicación (ganas de tirarlo a la basura ...). Esto suele pasar entre los usuarios de la cultura occidental; considero que en este punto se expresa la diferencia de la apropiación del celular entre los usuarios de esta y los huicholes. Mis informantes no han llegado al punto de estar hartos de comunicarse a través del celular, al punto de tener las ganas de tirarlo a la basura porque no cumplió con sus expectativas de inmediatez.

Esto explica su uso moderado de celular, no tienen la costumbre de ver la pantalla del celular a cada rato, no tienen su oído fijo en el sonido del celular, por eso no los desespera. La inmediatez no es un rasgo propio de su cultura, no están acostumbrados a obtener o ver los efectos inmediatamente.

No obstante, dos informantes míos coincidieron en cierta desesperación de no poder comunicarse inmediatamente. Un informante me dijo que cuando no le tomaban la llamada, se preguntaba a sí mismo: “¿por qué tiene el celular, si no lo usa?" y mandaba el mensaje, porque sabía 
que la persona estaba fuera de la cobertura. Aunque de esta manera se acercan al uso del celular en la cultura occidental (desesperación de no poder comunicarse inmediatamente), controlan sus emociones.

Escriben los mensajes porque es más barato que las llamadas. Todos mis informantes mencionaron que por la expresión escrita limitada a 160 signos, que es el límite para un mensaje, abreviaban intentando mantener la comprensión. Los mensajes se escriben, ante todo, en español, porque con los mensajes se comunican no solamente con los otros huicholes, sino con sus compañeros de clases y trabajo. A la vez mencionaron el problema de la confusión; por ejemplo, cuando ponían "Todo está bien”, el otro no entendía qué había querido decir con esto. Por eso prefieren enviar los mensajes sencillos y explicativos, p.e. "voy a ir mañana".

El uso escaso de mensajes (y no excesivo como en la cultura occidental) se expresa en la siguiente respuesta: "Normalmente yo no escribo mensajes así, largos, no, simplemente sencillos, y eso porque si es necesario, pero, si me voy, por ejemplo, con mis primos, para qué les escribo, porque ya voy, pero normalmente, pues, mensajes chicos. (...) Simplemente, mañana llego allí, pero ellos ya saben qué, qué voy a hacer, qué vamos a hacer." Exactamente, en "para qué les escribo, si voy", consiste la diferencia entre el uso moderado o escaso y exagerado.

Al uso moderado de los mensajes refiere el comentario de un informante quien mencionó que no iniciaba la comunicación a través de mensajes, sino que respondía a los mensajes que obtenía. Así ilustra el uso moderado de celular y más pasivo (ser ubicable) que activo (ubicar a los otros), y que se adecuaron de la posibilidad técnica -enviar los mensajes- por la escasez de recursos económicos.

Su desinterés por las innovaciones está presente en el hecho de que ni han investigado qué son los "emoticones". En primer lugar, tenía que explicarles qué eran los emoticones (en inglés smilings), aunque esta palabra se utiliza diariamente entre los jóvenes que utilizan los celulares. Luego me respodieron que no sabían usarlos o que no los tenían en su celular. No saben qué se hace con los puntos y comas en el teclado del celular. Sin embargo, unos mencionaron que sus amigos les mandaban estas expresiones de emociones.

A favor de su uso desinteresado, argumentan que tampoco se interesan por los nuevos tonos y melodías que pueden grabar en sus celulares, 
o comprar, ni investigan cómo se graban o dónde pueden conseguirse. Realmente no se interesan por todas las funciones y posibilidades que ofrece un celular.

Mis informantes coincidieron en el uso de la calculadora y el despertador; uno tenía toda su agenda (las cosas que tiene que hacer) en el celular. Usan las funciones que están en el celular, no buscan las innovaciones, ni se interesan sobre las innovaciones.

En el caso de los juegos del celular, ya depende del individuo, unos los juegan en el camión para distraerse. Esto significa que los huicholes tienen el uso moderado de los juegos en sus celulares; si los tienen, los aprovechan durante sus viajes en el transporte público, no juegan en su casa. Su desinterés por las innovaciones sugiere el hecho de que no se interesan por los juegos nuevos ni por la posibilidad de grabarlos de internet o comprarlos.

Los padres huicholes coincidieron en que sus hijos tomaban los celulares para jugar. Esto ilustra que a estos niños les atraen como a los niños de la cultura occidental. Sin embargo los padres les permiten solamente dos o tres juegos, porque los niños gastan la pila o bloquean el celular. Esto ilustra el valor de este para los huicholes: no representa cualquier objeto, sino uno caro que hay que cuidar.

Sin embargo, otro informante me dijo que él mismo jugaba con su celular, que lo tomaba como un juguete; una vez se le cayó y se rompió. Todo esto presupone la percepción del medio mismo como juguete y como medio útil y caro para comunicar.

Mis informantes dijeron que estaban contentos con los celulares que tenían, que en el futuro podría ser que compraran uno nuevo, pero que para llamar y enviar mensajes sus celulares son suficientes. A dos estudiantes/trabajadores huicholes les gustaría en el futuro comprar uno con el que podrían conectarse a internet, y uno de ellos quería, a la vez, uno con el que podría tomar fotos, porque su cámara se había descompuesto. Me dijo que en vez de comprar una cámara nueva compraría uno con estas dos funciones, pero no quería exagerar; el otro se preocupaba por los daños que podría causar el uso de esos aparatos. Ambos expresaron cierta moderación ante las innovaciones tecnológicas del celular, pero parece que la convergencia de las tecnologías en él (por su utilidad) atrae a los huicholes. 
Aunque les gustan los celulares nuevos, son conscientes de que no es necesario tenerlos con innovaciones. En el momento de la compra razonan la utilidad del medio como objeto.

Durante las entrevistas me enteré del uso de los celulares entre los jóvenes en la sierra y de la ciudad. Los primeros (le dicen a sus padres o trabajan para comprar el celular) llaman por este medio a las chicas huicholas que están en la ciudad. En este caso, el celular ha subrayado el matiz de libertad individual que tiene en las relaciones entre los jóvenes huicholes, que pueden comunicarse a través de los celulares sin que los otros huicholes se den cuenta que a uno le gusta una y viceversa.

\section{CONCLUSIONES}

Los huicholes tienen el uso instrumental, moderado y escaso de los medios, les falta capital "informático" (epistemología de medios, no saben cómo funcionan los medios, para qué les pueden servir) y formar una postura crítica ante los medios.

No obstante, los huicholes que viven en la ciudad, por el carácter del mundo en que se mueven diariamente ${ }^{33}$, están más intensamente en contacto con los medios que los huicholes vividos en las comunidades en la sierra. A pesar de esto, tampoco tienen la necesidad ni la constumbre de interactuar con ellos muchas horas diariamente. Se apropiaron de la televisión y de la radio, pero tampoco la consumen tanto como se suele hacer en la cultura occidental, porque tienen otras cosas que hacer (p.e. artesanías para vender, tareas). Su uso escaso de la televisión proviene de la falta de tiempo libre para verla y de las preferencias que tienen.

A pesar de que les gustan las películas, no salen al cine por los escasos recursos económicos (aceptan las invitaciones); prefieren ahorrar para gastar en otra cosa que en el cine y además no tienen la costumbre de ir.

Los huicholes que estudian en la ciudad están en contacto más intenso con los medios; usan el periódico e internet, porque el mundo académico en el que están lo exige. Sin embargo, a la vez hablan sobre

33 Ven publicidad a cada paso, ven los periódicos por las calles, ven a la gente usando los celulares como si fuera algo natural y necesario para vivir. 
su interés en cierto tipo de noticias que salen en el periódico y saben cómo el periódico puede servirles.

Por los rasgos de su cultura, los atrae más lo audiovisual que lo letrado. Todos los huicholes se apropiaron de la televisión y de la radio porque coinciden con los rasgos de su cultura; su uso es moderado y escaso (por tener otras preferencias y la carencia de tiempo libre); no tienen una postura crítica ante estos medios. A pesar de que representan sus únicas fuentes de información, los usan como meros medios de difusión.

El uso que los estudiantes hacen de la computadora e internet es intrumental, les falta capital "informático" (epistemología de medios). De los libros leen los manuales, no tienen la costumbre de leer por el placer de la lectura.

En la apropiación de los medios se nota la diferencia entre los estudiantes huicholes que viven en la ciudad y los que viven en la sierra.

Todavía queda una parte del perfil comunicativo que no he investigado: las diferencias en los usos de los medios según el género. Parece que hay una diferencia en el uso de internet entre los géneros y en el uso de la televisión, según lo que me dijeron las mujeres entrevistadas.

Por ser el medio de comunicación entre la ciudad y la sierra, los huicholes de la ciudad se apropiaron del celular. Estos lo compran para ser ubicables en la ciudad, ante todo por sus familiares que están en la sierra. Otra razón ya no tan destacada es tener el celular como objeto proveniente de la cultura occidental en la que se mueven y que de cierta manera lo exige (por causa de trabajo y estudios). Una vez que ya tienen el celular comprado, lo usan para comunicarse con los otros huicholes de la ciudad, con sus compañeros de clases.

Realmente, los huicholes exponen las mismas razones de compra que en la cultura occidental: el celular como medio global de la comunicación está elaborado para convenir en todas las culturas del mundo, tanto la huichola como la occidental, lo que es específico en el caso de los huicholes es el uso de celular. Se sienten gratificados por las funciones básicas del aparato: llamar, enviar los mensajes. Usan las funciones que están en el despertador, calculadora, juegos, pero no se interesan por las innovaciones. Esta es la diferencia del uso del celular entre los huicholes, no se interesan por sus posibilidades (p.e. el uso de los emo- 
ticones) y por las innovaciones (grabar los tonos y melodías). El uso que hacen del celular es instrumental.

Lo destacable es que los huicholes utilizan el celular más para recibir las llamadas que para llamar, por razones económicas. Igualmente escriben los mensajes por estas razones, porque sale más baratos, la mayoría de ellos están más dispuestos a recibir los mensajes que a enviarlos. Tienen otros recursos para comunicarse además del celular: el encuentro dominguero (medio barato y a la vez importante por el rasgo comunitario, colectivo de la sociedad huichola) y los teléfonos públicos, en algunos casos el correo electrónico. El celular lo usan en los casos de emergencia, cuando no pueden esperar o arreglar el asunto de otra manera.

Los huicholes ni extienden sus números de celular ni se los piden a sus amigos huicholes de la ciudad, como se acostumbra en la cultura occidental. Ya describí las dificultades de conseguir un número: un informante me dijo que no tenía ningún número de celular de los huicholes radicados en la ciudad; la lista de números de celulares de otro informante no ocupa ni una hoja en su agenda. Esto ilustra que el celular, para la comunicación con otros huicholes que viven de la ciudad, no es importante; en la ciudad tienen otros recursos para encontrar a sus amigos. Esto implica que como medio de comunicación es más importante para la que establecen con sus familiares en la sierra y con los mestizos de la ciudad (trabajo, estudios). Esto sugiere el hecho de que cuando están en la sierra no usan el celular o lo usan para pasar los recados de los huicholes que viven en la ciudad.

Cada uno de mis informantes se diferenciaba en la apropiación del celular: uno está más dispuesto a comunicarse (lo lleva encendido en la sierra) que los otros, unos lo llevan cada día (sin celular ya se sienten que les falta algo), los otros no (no les dan ganas). A pesar de las diferencias personales según el grado de la integración del celular en su vida cotidiana, su uso es moderado, no tienden a exagerarlo. Por eso cuando no cumple con sus expectativas de comunicación inmediata, no se desesperan tanto y no filtran sus emociones por este medio.

Los huicholes tienen otras preferencias (tareas, trabajo) que estar dispuestos a comunicarse en todo momento. Apagan el celular por la noche, en el trabajo, si necesitan concentrarse, y en las clases o, por lo 
menos, le quitan el sonido señal de respeto al maestro. Tampoco envían mensajes a cada rato.

Su apropiación del celular oscila entre dos modos: estar ubicable y dispuesto a comunicarse, y sus preferencias: centrarse en otras actividades más importantes para los huicholes, para la comunidad (sus estudios, por ejemplo).

El celular es el medio que subraya los matices de libertad personal, pero la cultura huichola se basa en lo comunitario, en lo colectivo. ¿De qué manera se expresa esta diferencia en el uso de los celulares?

Los huicholes se apropian de este medio individualmente, ya describí las diferencias en su apropiación; en lo que coinciden es que su uso es moderado, no tienden a exagerarlo y no se interesan por las innovaciones ni por todas las funciones o posibilidades del celular. El celular, para los jóvenes de la sierra, representa un medio para comunicarse con sus amigas y novias en la ciudad; en este aspecto subraya los matices de su libertad individual.

A la vez, les conviene la convergencia de las tecnologías en el celular, pero no los impresiona, no quieren exagerar, ante todo valoran su utilidad.

Finalmente, el celular ha transformado la comunicación social de los huicholes por el simple hecho de usarlo, pero no ha influido al grado que en la cultura occidental, por razones económicas (escasez de recursos económicos) y culturales.

\section{Bibliografía}

BAZ, Margarita (1999) “La entrevista de investigación en el campo de la subjetividad" en Isabel Jáidar (comp.) Caleidoscopio de subjetividades. México: UAM-Xochimilco.

BIGLOW, B. M. (2001) Ethno-nationalist politics and cultural preservation: education and bordered identities among the Wixaritari (huichol) of Tateikita, Jalisco, Mexico. Ann Arbor: ProQuest Company.

CORONA Berkin, Sarah (2002a) "El discurso amoroso: Un escenario para estudiar la recepción" en Orozco Gómez, G. (coord.) Recepción y mediaciones. Caso de investigación en América Latina. Buenos Aires: Grupo Editorial Norma. 
- (2002b) Miradas entrevistas. Guadalajara: Pandora, S.A.

- (2004) "Educación indígena, educación política. El uso del periódico en la escuela wixarika", en Corona Berkin, S., Peza Casares de la, C. Educación indigena. En torno a la interculturalidad. Guadalajara: Universidad de Guadalajara.

- (2006) Evaluación a Tatei Yurienaka Iyarieya. Guadalajara: Fundación Ford.

GEERTZ, Clifford (1988) La interpretación de las culturas. Barcelona: Gedisa. http://redescolar.ilce.edu.mx/redescolar/publicaciones/publi_mexico/publihuicholes.htm, de primavera 2002, 22.8.2005

ITURRIOZ Leza, J. L. (1995) "Principios generales de la cultura huichola”. En Iturrioz Leza, J.L. Reflexiones sobre la identidad étnica. Guadalajara: UdeG.

MARTÍN-BARBERO, Jesús (2002) La educación desde la comunicación. Colombia: Norma.

- Rey, Germán (1999) Los ejercicios del ver. Barcelona: Gedisa.

OROZCO Goméz, Guillermo (2001) Televisión, audiencias y educación. Columbia: Norma.

PACHECO Salvador, I. (1995) "Los géneros de la tradición oral huichola”. En: Iturrioz Leza, J.L. Reflexiones sobre la identidad étnica. Guadalajara: UdeG.

RAJSBAUM Gorodezki, A.: http://cdi.gob.mx/ini/monografias/huicholes.html 22.8.2005

SARTORI, Giovanni (1998) Homo videns. La sociedad teledirigida. Madrid: Taurus.

TAYLOR, S.J., y Bogdan, R. (1998) Introducción a los métodos cualitativos de investigación. Barcelona: Paidós.

WINOCUR, Rosalía (2004) "La computadora y la internet como estrategia de inclusión y recurso de movilidad social en el imaginario de los pobres". En Corona Berkin, S., Peza Casares de la, C. Internet y televisión. Una mirada a la interculturalidad. Guadalajara: Universidad de Guadalajara. 